\title{
Competências em práticas letradas de estudantes de Ensino Médio no contexto da desordem informacional
}

\section{Ana Cláudia Bertini Ciencia* \\ Resumo}

Este artigo objetiva discutir competências de alunos de Ensino Médio em práticas sociais de leitura e escrita mediadas por mídias digitais, no contexto da desordem informacional e no tocante à identificação de informação falsa. O estudo ancorase nos pressupostos dos Novos Estudos de Letramentos (New Literacy Studies), especificamente no que se refere à formação do leitor, a partir dos quais se descrevem e discutem orientações da Base Nacional Comum Curricular (BNCC). O conjunto do material é formado por 105 produções textuais coletadas em uma escola pública de São José do Rio Preto, interior de São Paulo, no primeiro semestre de 2019. Embora tanto a coleta do material quanto a BNCC sejam anteriores à pandemia da covid-19, faz-se pertinente problematizar também essa crise sanitária, a qual potencializou um contexto de "infodemia" e evidenciou desigualdades no acesso à educação. A análise dos dados demonstra que os estudantes de Ensino Médio são competentes em reconhecer informação falsa com base em critérios relacionados ao uso de norma culta. No entanto, parecem desconhecer questões não relacionadas diretamente a aspectos linguísticos e ignorar o atravessamento de vozes e crenças particulares no processo da desordem informacional. $\mathrm{O}$ trabalho aponta para o confronto entre as expectativas e orientações da BNCC e os letramentos que precisam ser discutidos e trabalhados pela instituição escolar, pensando, principalmente (mas não apenas) numa vida pós-pandemia.

Palavras-chave: Letramentos midiáticos e informacionais. Formação do leitor. BNCC. Ensino Médio.

\footnotetext{
Universidade Estadual Paulista "Júlio de Mesquita Filho". Aluna do curso de Doutorado em Estudos Linguísticos. ORCID: https://orcid.org/0000-0001-6327-3805. Este trabalho está associado ao projeto Literacies in Different Fields of Knowledge, no âmbito do Programa Capes-PrInt, processo no ${ }^{\circ} 88887.310463 / 2018-00$.
} 


\title{
High Students' Competences in Literacy Practices in the Information Disorder Context
}

\begin{abstract}
This article discusses High School students' competences in reading and writing social practices in digital media, in the information disorder context and related to false information. The theorical framework is based on the New Literacy Studies, particularly in the reader formation, from which orientations of the Base Nacional Comum Curricular (BNCC - Common Core Curriculum) are described and discussed. The approach is based on qualitative and interpretative methods, concerning 105 textual productions written by students from a public school in São José do Rio Preto, São Paulo countryside, in 2019 first semester. Although both the 105 compositions and the BNCC are previous to the covid-19 pandemic, it is relevant to discuss this sanitary crisis, which has demonstrated an "infodemic" context and emphasized inequal education access. Data analysis showed that High School students are capable in recognizing false information based on Portuguese language criteria. However, they seem to ignore aspects that are not related to linguistics, as well as discourses and personal beliefs in information disorder process. The results show a conflict between expectations and guidance of the BNCC and literacies that must be discussed and developed by schools, mainly (but not only) considering a post-pandemic life.
\end{abstract}

Keywords: Media and information literacy. Reader education. BNCC. High School.

Recebido em: 12/07/2021 // Aceito em: 10/09/2021. 


\section{Introdução}

Com base em pressupostos dos Novos Estudos de Letramento (New Literacy Studies), especialmente no campo da discussão sobre letramentos midiáticos e informacionais, este trabalho tem como objetivo principal discutir competências de alunos de Ensino Médio em práticas sociais de leitura e escrita em mídias digitais, levando em consideração a conjuntura daquilo que Wardle e Derakhshan (2017) denominaram "desordem informacional". Para tanto, propõe-se discutir orientações da Base Nacional Comum Curricular (BNCC) do Ensino Médio (2018) no tocante à formação do leitor, tendo em vista o enfrentamento à desinformação num contexto de pós-verdade atravessado não apenas por aspectos textuais, mas também sociais, emocionais e discursivos. Essas orientações são confrontadas com um conjunto de material formado por 105 produções textuais escritas, produzidas por alunos de Ensino Médio de uma escola pública de São José do Rio Preto, no interior de São Paulo, no primeiro semestre de 2019.

Tanto a coleta do material quanto a redação da BNCC são anteriores à covid-19, doença cuja pandemia, decretada em março de 2020, acentuou desigualdades de acesso à educação e deflagrou aquilo que Zarocostas (2020) nomeou como "infodemia", em referência ao comportamento massivo e constante de disseminação de conteúdo falso ou enganoso sobre a doença. Porém, a problematização acerca da desinformação é também prévia à crise sanitária - e, portanto, coerente com uma discussão feita com base no conjunto de atividades apresentado. Além disso, acreditamos que seja do interesse dos estudos de letramentos o diálogo (ou o confronto) entre as expectativas institucionais e as produções reais de estudantes de Ensino Médio em práticas sociais letradas. 
Assim, na primeira seção, o artigo apresenta o contexto de origem da BNCC, discute brevemente alguns avanços e controvérsias do documento e aponta suas expectativas no tocante à formação do aluno em relação às fake news e à pósverdade. Em seguida, aborda o papel do leitor e a importância de sua formação com base nos estudos de letramentos; destacam-se, nessa parte, alguns dados referentes ao impacto da pandemia da covid-19 sobre a educação e os letramentos. Na terceira seção, descreve a atividade aplicada aos alunos de Ensino Médio e, em seguida, discute os dados resultantes da análise do conjunto do material. Ao final, reflete sobre as competências já demonstradas pelos estudantes em suas produções, assim como aponta aquilo que ainda precisa ser problematizado e discutido pela instituição escolar na formação do leitor para uma vida durante e pós pandemia.

\section{A Base Nacional Comum Curricular: origem, avanços e controvérsias}

A Base Nacional Comum Curricular (BNCC), de 2018, é um documento que define, de maneira unificada para todo o país, as aprendizagens essenciais a serem desenvolvidas pelas instituições escolares públicas e privadas. É caracterizada oficialmente como "política pública" que serve de referência para a elaboração dos currículos da educação básica.

O surgimento do documento se dá num contexto de questionamento e revisão do currículo como modelo de aprendizagem vertical, ao final do século XX. Nesse modelo, o currículo é tido como um processo de acúmulo de conteúdos acadêmicos decididos e distribuídos pelo Estado. 
Autores como Moreira (2001) e Morgado (2012, porém, defendem o currículo como um processo que englobe a matriz sociocultural em que se insira. Em outras palavras, além de compreender aspectos conteudistas, o currículo dialogaria com um paradigma socioeducativo; constituir-se-ia, portanto, um processo de construção dinâmico, que levaria em consideração particularidades da comunidade na qual seria aplicado.

Em 1996, a Lei de Diretrizes e Bases da Educação Nacional (LDB) determinou a criação de uma base comum para a educação básica brasileira. No entanto, apenas em 2015 dá-se início à elaboração do texto da base, após o Plano Nacional de Educação (BRASIL, 2014) definir sua criação como estratégia para que se atingissem metas educacionais.

A primeira versão da BNCC foi elaborada em 2015, constituída de contribuições sociais vindas de consulta pública. Em 2016, a segunda versão migrou pelos estados brasileiros, onde foi submetida a leitura e debates entre os educadores. Finalmente, após uma última rodada de seminários e debates, a BNCC foi homologada pelo MEC em dezembro de 2017; a etapa do Ensino Médio seria homologada um ano depois, em dezembro de 2018.

A elaboração de uma base comum para a educação de todo o Brasil, além de obedecer à determinação da LDB (BRASIL, 1996), segue uma tendência internacional de mudanças em sistemas educacionais, visando a chamada equidade no aprendizado, colocada em prática por países como Austrália, Portugal, França, Estados Unidos e Chile, conforme a própria BNCC (BRASIL, 2018, p. 13). Observa, ainda, o fato de que países como Finlândia e Coreia do Sul, ambos com alto desempenho nas avaliações do Programme for International 
Student Assessment (PISA, sigla traduzida como Programa Internacional de Avaliação de Alunos), coordenadas pela Organização para a Cooperação e Desenvolvimento Econômico (OCDE), lançam mão desse tipo de diretriz unificada.

Destarte, a BNCC representa um avanço em relação ao modelode aprendizagem vertical na medida em que, teoricamente, supera o mero delineamento de disciplinas e conteúdos em prol de competências e habilidades às quais os estudantes teriam direito. Ainda que constitua uma diretriz unificada, levaria em consideração particularidades das comunidades escolares.

No entanto, convém também levantar, ainda que brevemente, alguns aspectos controversos do documento. Entre as vozes dissonantes, podem ser citadas as professoras Aurina de Oliveira Santana, Malvina Tania Tuttman e Marcia Ângela da Silva Aguiar, conselheiras do Conselho Nacional de Educação (CNE) cujos votos foram contrários à aprovação da base, em dezembro de 2017, sob a argumentação de incompletude e limitações do texto e necessidade de ainda ampliar o diálogo de modo democrático (UNIVERSIDADE FEDERAL FLUMINENSE, 2018). Gontijo (2015) e Silva (2015) também tecem uma análise crítica ao considerar os problemas da BNCC quanto à alfabetização (cujo conceito é reduzido a uma noção de instrumentalização das práticas de leitura e escrita) e aos "cenários de disputa" (SILVA, 2015, p. 368) em torno do Ensino Médio. Para as autoras, há controvérsias quando se consideram os objetivos últimos que atravessam o texto da base - embora o discurso seja voltado a competências e direitos dos estudantes, o viés ainda é utilitário e submetido a desempenho e resultados de avaliações. As análises se fazem coerentes ao se considerar, por exemplo, a influência das diretrizes da OCDE (uma instituição 
econômica, não educacional) na constituição do documento. Fica clara, assim, a submissão à lógica de avaliações em larga escala e a concepção da educação para uma finalidade utilitária.

Neste trabalho, nosso propósito não é nos aprofundar na discussão acerca dos avanços e limitações da BNCC. ${ }^{1}$ Apresentado, então, seu contexto de origem e um breve panorama das discussões relacionadas às suas vantagens e controvérsias, debrucemo-nos, em seguida, sobre as habilidades relacionadas à formação do leitor no tocante às fake news e à pós-verdade.

\subsection{A competência leitora, a desordem informacional e as habilidades na BNCC: expectativas institucionais}

Antes de passarmos aos pressupostos dos Novos Estudos de Letramentos no que diz respeito ao leitor, convém observarmos como a BNCC (BRASIL, 2018) aborda conceitos como leitura e letramento e, consequentemente, quais as suas expectativas no que diz respeito às habilidades a serem desenvolvidas no contexto da desordem informacional.

A "leitura", no documento, é compreendida com frequência num âmbito associado à escuta e à produção; constitui, conforme o próprio texto, um eixo de integração correspondente a uma prática de linguagem. Nessa conjuntura, o leitor é concebido como o agente dessa atividade, alguém que compreenda os sentidos do texto ${ }^{2}$ e possa dele fruir.

\footnotetext{
1 A esse respeito, é pertinente a mesa-redonda conduzida por Freitas e Pietri (2021), na ocasião do $68^{\circ}$ Seminário do Grupo de Estudos Linguísticos (GEL).

2 A base - ao menos na etapa do Ensino Médio - não conceitua ou discute o conceito de leitor, nem a questão do sentido e seu processo de construção ou mesmo a concepção de texto. Neste trabalho, não problematizamos tais concepções de um ponto de vista teórico, mas as analisamos e discutimos no conjunto do material com base nos Novos Estudos de Letramento. Ainda assim, vale frisar que sentimos falta de uma indicação explícita das bases epistemológicas que nortearam certas concepções na BNCC; conceitos, afinal, são palco de disputas, e não consensos teóricos.
} 
Na etapa do Ensino Médio, o texto da BNCC confere maior destaque à chamada cultura digital e aos novos e multiletramentos. Considera a hibridização de papéis em mídias digitais e redes sociais - compreende, portanto, que o leitor é, ao mesmo tempo, produtor de conteúdo. Sua postura, nesses ambientes, é ativa, visto que, associadas à leitura, estão ações como curtir, comentar e compartilhar. Faz-se necessário, então, "que os estudantes desenvolvam habilidades e critérios de curadoria e de apreciação ética e estética, considerando, por exemplo, a profusão de notícias falsas (fake news), de pós-verdades e de discursos de ódio nas mais variadas instâncias da internet e demais mídias." (BRASIL, 2018, p. 479).

O documento da base, então, identifica duas habilidades essenciais no que diz respeito especificamente ao enfrentamento da desinformação e à postura do estudante no contexto da pósverdade, explicitando preocupação quanto à veracidade de informações, ao atravessamento de argumentos por crenças pessoais e à preservação do respeito diante de discursos de ódio. Essas habilidades são reproduzidas na Figura 1:

\section{Figura 1 - habilidades relacionadas à desordem informa- cional}

(EM13LP38) Usar procedimentos de checagem de fatos noticiados e fotos publicadas (verificar/avaliar veículo, fonte, data e local da publicação, autoria, URL, formatação; comparar diferentes fontes; consultar ferramentas e sites checadores etc.), de forma a combater a proliferação de notícias falsas (fake news).

(EM13LP39) Analisar o fenômeno da pós-verdade - discutindo as condições e os mecanismos de disseminação de fake news e também exemplos, causas e consequências desse fenômeno e da prevalência de crenças e opiniões sobre fatos -, de forma a adotar atitude crítica em relação ao fenômeno e desenvolver uma postura flexível que permita rever crenças e opiniões quando fatos apurados as contradisserem.

Fonte: Brasil (2018, p. 511) 
Fica claro, portanto, que a BNCC tem uma expectativa quanto ao desenvolvimento da competência leitora dos estudantes. Ao final da educação básica, o aluno deverá estar apto a não apenas ler e compreender um texto veiculado em ambientes digitais, mas também a atuar sobre ele de forma crítica, seja comentando e curtindo ou, principalmente, aplicando critérios de curadoria e análise do conteúdo, de forma a identificar conteúdo falso e evitar seu compartilhamento. Espera-se, também, que o estudante possa ser capaz de perceber e problematizar a formação de filtros bolha e câmaras de eco e a ascensão de crenças pessoais como único parâmetro de julgamento - contexto que McIntyre (2018) denomina como "pós-verdade".

De encontro a essas expectativas, porém, vão críticas relacionadas ao déficit da educação brasileira e à falta de igualdade e de equidade de oportunidades de estudo (ou mesmo de acesso à educação) -, obstáculos sensivelmente potencializados pela pandemia da covid-19. Os usos da leitura (e também da escrita) em práticas sociais letradas se veriam, assim, impactados por essa desigualdade. É nesse panorama de conflitos que delineamos, a seguir, o papel do leitor à luz dos pressupostos dos Novos Estudos de Letramentos, assim como discutimos alguns dados referentes ao impacto da crise sanitária na educação e no enfrentamento da desordem informacional.

\section{A desordem informacional, o leitor e os letramentos}

Da perspectiva da comunicação e informação, Tandoc Jr., Lim e Ling (2018) argumentam que o fenômeno das fake news em si - entendido em linhas gerais como "notícias intencional e comprovadamente falsas que poderiam desorientar os leitores" 
(ALLCOTT; GENTZKOW, 2017 apud TANDOC; LIM; LING, 2018 , p. 138, tradução nossa) ${ }^{3}$ - não é novo. Os autores trazem como exemplo a narração de um trecho da obra A guerra dos mundos, de H.G. Wells (1898), em transmissão radiofônica ao vivo por Orson Welles, em 1938, a qual ilustra não só a divulgação de uma informação falsa como também o pânico que tomou conta de boa parte da população que teve contato com a suposta notícia de invasão alienígena.

O que é novo, porém, é o contexto de produção, divulgação e recepção de tais notícias. Em outras palavras, a internet, as redes sociais e o uso constante (e quase indiscriminado) de dispositivos móveis com acesso a esses recursos possibilitaram uma mudança radical nos papéis dos envolvidos na comunicação e na produção de sentidos. Na contemporaneidade, consideram-se as eleições nos Estados Unidos, em 2016, como potencializadoras do aumento de um número expressivo de notícias, boatos e disseminação proposital de mentiras - logo, o termo fake news teve sua ascensão e caiu no conhecimento público nesse mesmo ano.

Trata-se, no entanto, não de um entendimento simplista do que é verdadeiro ou falso, mas daquilo que Wardle e Derakhshan (2017) avaliaram como "desordem informacional", fenômeno amplo potencializado após a votação do Brexit e da eleição estadunidense de 2016. Os autores se baseiam em critérios de tipo de informação e intencionalidade; conforme essa tipologia, conteúdo falso seria chamado de misinformação; já a informação danosa é conceituada malinformação. A desinformação, por fim, da qual as fake news seriam apenas uma parte, ocorre quando o conteúdo é comprovadamente inverídico e tem intenção de

3 No original, em inglês: "to be news articles that are intentionally and verifiably false, and could mislead readers [...]". 
causar prejuízo. Faz-se necessário, nesse contexto, discutir os letramentos e seu papel na relação com tal tipo de conteúdo.

Com base nos pressupostos dos Novos Estudos de Letramento (New Literacy Studies), não se trata de considerar um modelo autônomo de práticas sociais de leitura e escrita, como já apontava Street (1984), em que o leitor competente, proficiente em decodificar o código linguístico, teria controle sobre as escolhas do que lê e sobre a própria construção de sentidos advinda dessa leitura. Em vez disso, trata-se de considerar um modelo ideológico, atravessado por relações de poder e diálogo entre vozes que se estabelecem e se ocultam no campo discursivo.

Lankshear e Knobel (2015) ampliam os muitos letramentos que podem ser identificados em diferentes contextos sociais. No cenário das fake news, emergem os letramentos midiático, digital e informacional, os quais se relacionam não apenas à competência ao fazer uso das mais diferentes mídias, mas também dialogam com leitura, entendimento de conteúdo e curadoria daquilo que é necessário ou mesmo relevante. Koltay (2011), por sua vez, chama a atenção, ainda, para a possibilidade da produção de conteúdo - ainda que esta seja bem menos considerada do que sua recepção - como aspecto relevante no contexto de letramento, visto que, em rede, a possibilidade e a facilidade de fazê-lo são não só altas como também estimuladas; pode-se afirmar, portanto, que se considera uma espécie de hibridização de papéis.

Organismos internacionais como a Câmara dos Comuns e o High Level Expert Group (doravante HLEG, Grupo de Alto Nível da Comissão Europeia) entendem também o fenômeno da desinformação como algo mais amplo do que a mera 
conceituação de fake news. Dentre as recomendações publicadas no relatório de 2018 do HLEG estão, além do desenvolvimento de ferramentas de checagem e da transparência na divulgação de notícias online, o estímulo a estudos científicos sobre o impacto da desordem informacional e a "promoção de competências em educação para a mídia”. Em diálogo com esta última e buscando cumprir o Artigo 19 da Declaração Universal dos Direitos Humanos, que versa sobre liberdade de expressão e opinião, a Organização das Nações Unidas para a Educação, a Ciência e a Cultura (UNESCO) desenvolve a iniciativa Media and Information Literacy (MIL - no Brasil, Alfabetização Midiática e Informacional), a qual busca promover acesso equânime a informação e conhecimento, com ênfase na formação de professores. (UNESCO, 2019).

Os relatórios e discussões a respeito dos letramentos, como é possível perceber, demonstram expectativas acerca da formação do leitor - inclusive em contexto escolar e acadêmico - e seu papel protagonista no processo de desinformação já há alguns anos. No entanto, a preocupação com a emergência do fenômeno se potencializou notadamente durante a pandemia da covid-19, como se verá adiante.

\section{1 covid-19, desinformação e letramentos}

O impacto da catástrofe sanitária, que até o dia 4 de julho de 2021 já havia vitimado 524.417 pessoas no Brasil, conforme dados da universidade norte-americana Johns Hopkins (JOHNS HOPKINS UNIVERSITY, 2020, tem se mostrado nos mais diversos setores nacionais. Na educação, nosso foco de interesse neste trabalho, a pandemia não só acelerou o processo de ensino 
a distância como também acentuou as desigualdades sociais no tocante ao acesso a aulas e materiais digitais e à continuidade dos estudos versus a impossibilidade de se ter um espaço adequado para tal, munido de equipamentos tecnológicos básicos, ou a urgência em procurar um emprego e deixar os mais velhos em casa, em isolamento.

Tanto a aceleração do processo de ensino à distância quanto a acentuação das desigualdades foram situações consideradas catalisadoras do abandono das atividades escolares, segundo a terceira edição do Painel TIC-Covid 19, publicada em novembro de 2020. ${ }^{4}$ O relatório aponta que, no Brasil, 32\% dos usuários de Internet com idade igual ou superior a 16 anos frequentavam escola ou universidade no terceiro trimestre de 2020 (período no qual a pesquisa foi desenvolvida). Como barreiras para a continuidade dos estudos, os respondentes indicaram dificuldades para esclarecer dúvidas com os professores $(38 \%)$, baixa qualidade de conexão $(36 \%)$ e falta de estímulo para estudar (33\%).

Os dados dialogam com Komesu, Daunay e Fluckiger (no prelo); para os autores, se a tecnologia foi a principal ferramenta responsável pela manutenção das atividades escolares, paralela e paradoxalmente foi também aquilo que dificultou e impediu que essas tarefas fossem feitas. Os autores criticam o "panorama ideal" de continuidade dos estudos em confronto com desigualdades sociais relacionadas à qualidade de equipamentos e conexão à rede, condições de estudo em casa, hábito e proficiência no uso dos recursos tecnológicos.

\footnotetext{
4 Trata-se de um relatório elaborado pelo Centro Regional de Estudos para o Desenvolvimento da Sociedade da Informação (Cetic.br), departamento do Núcleo de Informação e Coordenação do Ponto BR (NIC.br), instituição civil que por sua vez é ligada ao Comitê Gestor da Internet do Brasil (CGI.br), criado por uma portaria Interministerial de maio de 1995 e com normas de funcionamento e atribuições regimentadas pelo Diário Oficial da União de 04 de setembro de 2003.
} 
Para além do impacto na educação, a pandemia deflagrou uma crise no âmbito da desordem informacional - daí o termo “infodemia" (ZAROCOSTAS, 2020). O relatório do Reuters Institute (NEWMAN, N. et al., 2021), produzido após pesquisa realizada em 46 países (com um total de 92.000 respondentes), destaca o potencial das mídias sociais para divulgação de desinformação. Dentre os entrevistados, 54\% afirmaram ter tido contato com postagens desinformativas sobre covid-19; no Brasil, especificamente, o WhatsApp e o Facebook foram as duas plataformas mais apontadas como responsáveis por compartilhamento desse tipo de conteúdo (indicado por $35 \%$ e $18 \%$ dos respondentes, respectivamente).

Merece destaque o trabalho de Islam et al. (2020), que examinaram rumores, comentários estigmatizados e teorias da conspiração de 87 países que circularam em plataformas online (incluindo agências de checagem) no período de dezembro de 2019 a abril de 2020. O grupo, formado por médicos, epidemiologistas e sociólogos, comparou e contrastou conteúdos jornalísticos com dados de outras fontes; os números levaram à conclusão de que as agências de saúde devem mapear a desinformação associada à covid-19 em tempo real e engajar esforços para combatê-la. No Brasil, Galhardi et al. (2020) desenvolveram um estudo empírico quantitativo acerca do teor das mensagens recebidas pelo serviço de checagem do aplicativo brasileiro "Eu Fiscalizo". Os autores referem-se a essa problemática como "uma segunda mazela pandêmica" (p. 4202), visto que, em diálogo com o que afirma Zarocostas (2020), o impacto da disseminação desses conteúdos não se dá apenas no conhecimento da população sobre o assunto, mas também contribuiria para o descrédito da ciência; como solução, Galhardi et al. (2020) defendem o aumento do nível de informações adequadas para a população. 
É nesse cenário - pandêmico, desinformativo, atravessado por vozes variadas e dissonantes - que se encontra o estudante de Ensino Médio, tendo ainda sua formação impactada pelo ensino (forçosamente, nesse caso) remoto. Convergem (ou divergem), nessa conjuntura, o contexto sócio-histórico, a formação desse leitor e as expectativas institucionais. Orientações da BNCC, desinformação e pós-verdade, crise sanitária - eis a conjuntura em que se fazem essenciais as reflexões sobre os letramentos, seus alcances e desafios, na formação do jovem leitor brasileiro. Passemos, assim, à análise de nosso conjunto de material, buscando identificar competências já demonstradas pelos alunos e delinear pontos frágeis que, para uma vida pós-pandemia, fazem-se urgentes.

\section{0 conjunto de material: metodologia e atividade apli- cada}

O procedimento investigativo utilizado para elaboração das atividades, coleta e análise do material é o paradigma indiciário, proposto por Ginzburg (1989) como forma de estudo qualitativo. $\mathrm{O}$ autor destaca que a habilidade investigativa seria natural do ser humano, proveniente de seus tempos em que caçava para sobreviver. A aptidão em procurar e decifrar pistas - ou seja, de observar e analisar detalhes - é o que Ginzburg propõe como modelo de análise científica, relacionado principalmente às ciências humanas. Em oposição ao chamado paradigma galileano, em que se observa a ocorrência de determinado fenômeno de modo quantitativo, o paradigma indiciário busca não a pluralidade estatística, mas a relevância do dado levantado. 
Nossa escolha pelo paradigma indiciário dialoga com trabalhos como os de Corrêa (2004) e Abaurre et al. (2012), os quais propõem análise de práticas letradas em contexto escolar à luz dessa mesma metodologia. Os autores corroboram a relevância da adoção de um método qualitativo, que se volte para determinados índices linguístico-discursivos que, se não constituem uma "regra", tampouco podem ser ignorados na análise do material.

O conjunto de material utilizado foi coletado no primeiro semestre de 2019 na disciplina de Língua Portuguesa, com alunos de Ensino Médio, de idades entre 15 e 17 anos, em uma escola da rede pública de São José do Rio Preto, interior de São Paulo; foram coletadas 105 produções textuais, resultantes da aplicação de uma atividade, descrita a seguir. $\mathrm{O}$ acesso à instituição foi possível devido ao contato estabelecido com a professora de Língua Portuguesa e a autorizações da coordenadora pedagógica e da diretora geral. Em classe, a atividade foi proposta sob responsabilidade da professora de Língua Portuguesa à época, constituindo uma tarefa escolar de aula - ou seja, sem atribuição de nota ou qualquer associação que pudesse soar como coercitiva aos estudantes. O procedimento ético de coleta do material foi submetido ao Comitê de Ética em Pesquisa (CEP) do Instituto de Biociências, Letras e Ciências Exatas (IBILCE) da Unesp, do qual obteve dispensa de avaliação.

A parte verbal dos exercícios propostos aos alunos, apresentada mais abaixo no Texto 1, consistia, primeiramente, em um enunciado que situava o aluno em um grupo familiar no WhatsApp - sendo este, segundo descrição no próprio site do aplicativo, uma ferramenta que surgiu como alternativa ao sistema de Short Message Service (SMS - em português, Serviço 
de Mensagens Curtas) e que possibilita o envio e recebimento de diversos arquivos de mídia, além de textos e chamadas de voz. Nesse suposto grupo, o aluno teria recebido mensagem de um parente sobre tema de interesse; sua tarefa era elaborar um texto escrito que respondesse à mensagem recebida de modo a explicar a veracidade (ou não) do conteúdo compartilhado naquele contexto, mobilizando argumentos que julgasse pertinentes.

A mensagem dizia respeito ao cancelamento do próprio aplicativo WhatsApp. Tal mensagem foi adaptada de um texto multimodal que circulou em redes sociais em maio de 2017, alterando-se a data da notícia para que esta ficasse mais próxima da aplicação da atividade. A motivação para a escolha da notícia foi o fato de o WhatsApp ser um dos aplicativos mais usados no país; ocupa o terceiro lugar nas preferências dos brasileiros por mídias sociais, com 91,7\% das escolhas dentre 150 milhões de usuários ativos desses recursos (que correspondem a 70,3\% da população total do país), conforme a pesquisa "Global Digital Report 2021”, produzida pela agência We Are Social em parceria com a plataforma de mídia Hootsuite. Logo, o cancelamento de um recurso como esse - principalmente por ser gratuito teria impacto direto na vida e na comunicação sociais de todos, inclusive dos próprios alunos. A proposta do exercício, então, era fornecer-lhes um texto cujo conteúdo diretamente influenciasse seu cotidiano. 


\section{Texto 1 - atividade aplicada \\ ATIVIDADE INDIVIDUAL A SER REALIZADA EM SALA DE AULA}

Uma tia muito querida, no grupo de WhatsApp da familia, compartilhou o texto seguinte. Você, o(a) estudante da familia, ficou responsável por dizer a todos se o texto é verdadeiro ou não. Explique po। que/como você chegou a essa conclusão, usando elementos do texto enviado por sua tia.

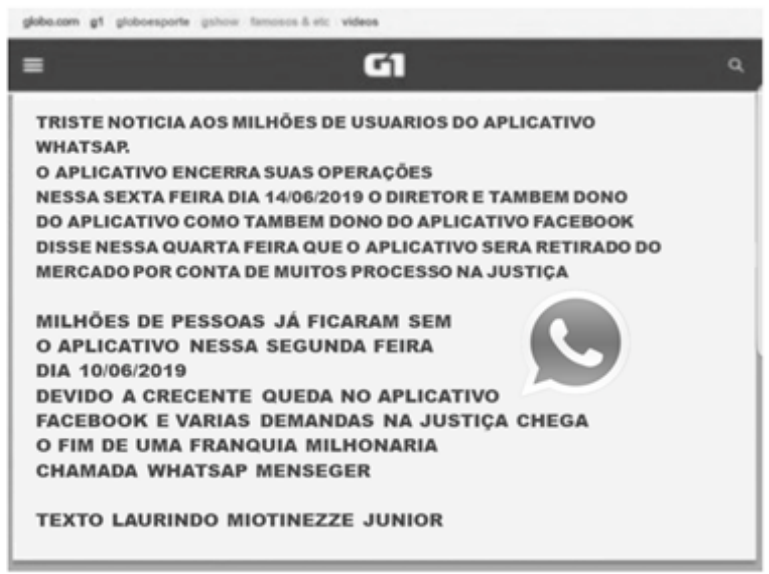

\section{ORIENTAÇÕES:}

- Redija seu texto obedecendo à norma culta da Língua Portuguesa.

- O texto deve ser escrito à caneta de tinta azul ou preta, no espaço apropriado, em até 20 linhas.

- Textos com até sete linhas escritas serão considerados "insuficientes".

- Serão também desconsideradas produções que contenham trechos desconectados do que é pedido ou termos inapropriados ao contexto.

Fonte: Dados da pesquisa (2021)

\subsection{0 estudante diante da desordem informacional: aná- lise dos dados}

Cerca de $90 \%$ dos respondentes identificaram o conteúdo veiculado no suposto grupo da família como sendo "falso". 5 No Gráfico 1, são apresentados os principais critérios levantados pelos estudantes nessa classificação (um mesmo estudante

5 Entre as respostas dos $10 \%$ restantes estão cópias da mensagem veiculada no suposto grupo da família, produções sobre Internet, WhatsApp ou privacidade (fora da proposta) e atividades entregues em branco. Não as consideraremos neste trabalho. 
pode ter apontado mais de um critério); escolhemos, para este trabalho, analisar os textos à luz dos critérios de "norma culta" e "experiência própria/empirismo" (primeira e quinta colunas do gráfico), por julgá-los significativos em relação às competências letradas que os estudantes já dominam e aquelas que ainda desconhecem no contexto digital da desordem informacional.

\section{Gráfico 1 - critérios para avaliação de informação}

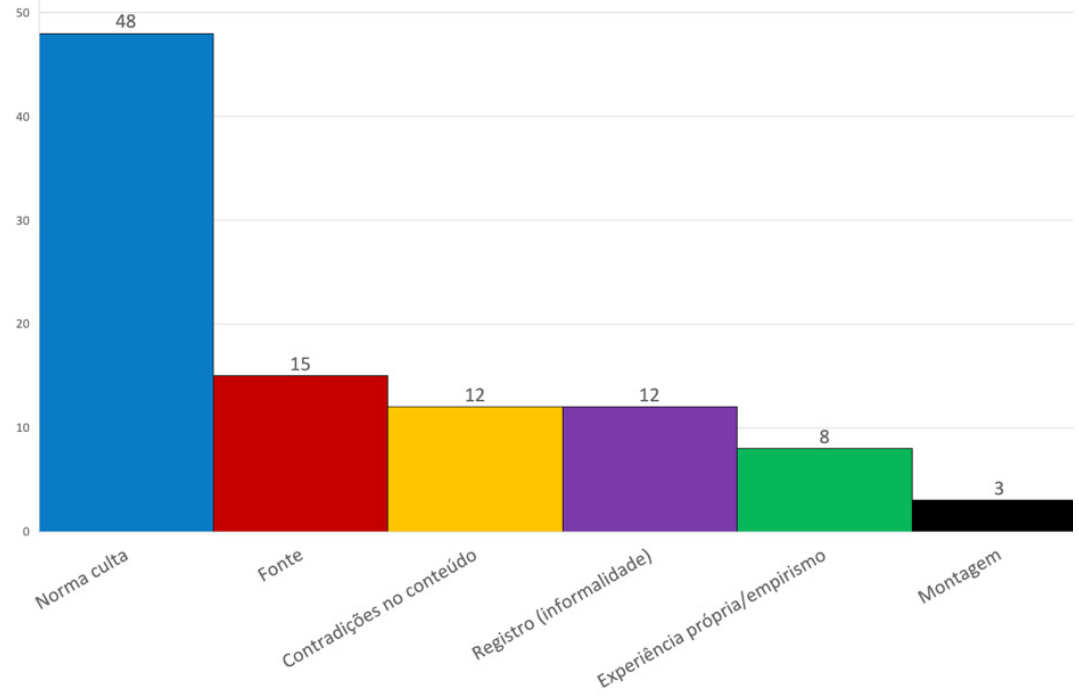

Fonte: Dados da pesquisa (2021)

Percebe-sequea avaliaçãodo conteúdoépredominantemente associada ao uso de "norma culta" feito pelo autor texto. Por meio de colocações relacionadas a desvios de ortografia, falta de pontuação e concordância, paragrafação indevida, repetição vocabular, $48 \%$ dos alunos julgaram a mensagem compartilhada pela tia como falsa. Tem-se um exemplo no Texto 2 : 
Competências em práticas letradas de estudantes de Ensino Médio no contexto da desordem informacional

\section{Texto 2 - produção textual de um respondente}

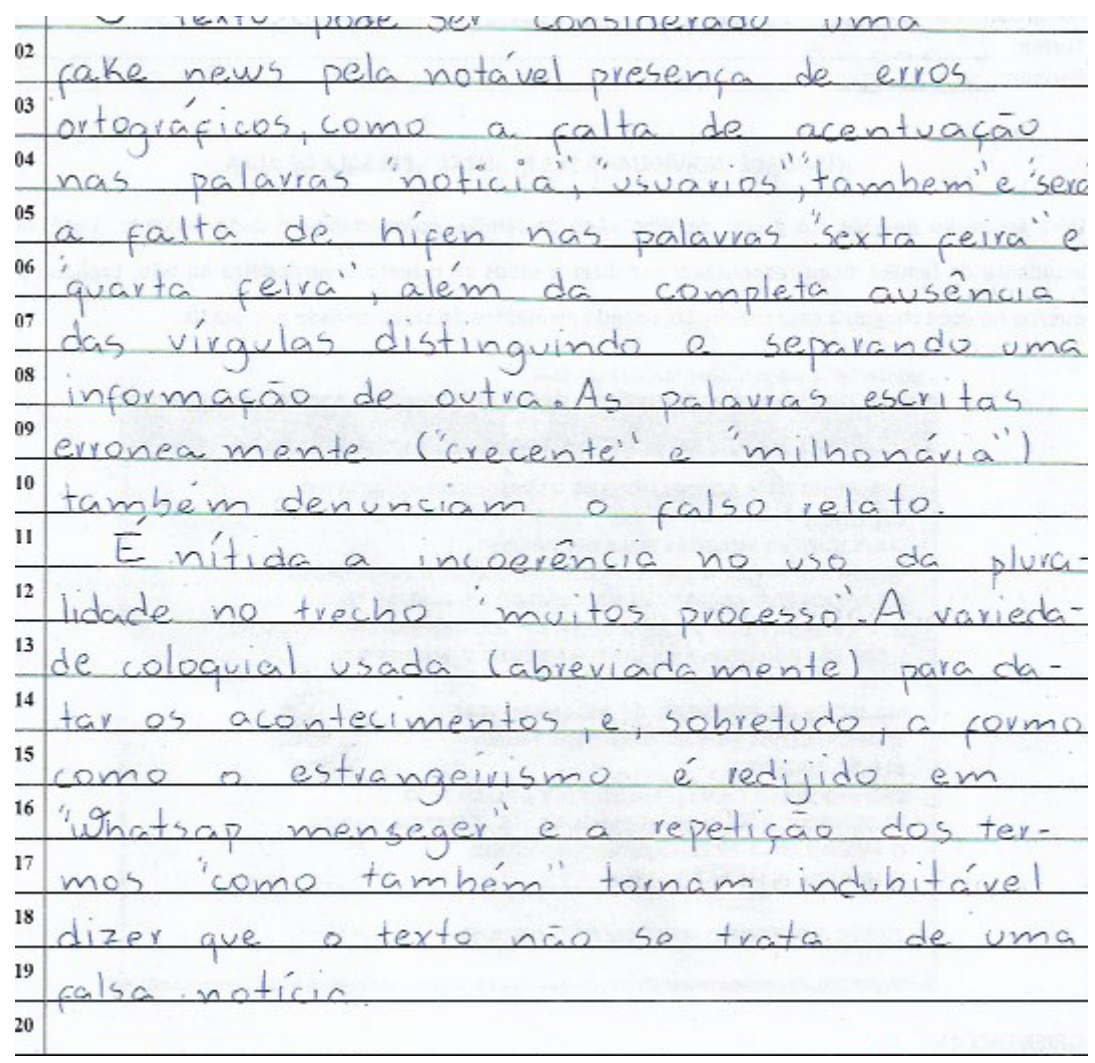

Fonte: Dados da pesquisa (2021)

O respondente - identificado doravante como R1 - lança mão de diversos exemplos de termos do próprio texto-fonte para justificar aquilo que chama de "erros ortográficos" (linhas 2 e 3). Não há, nesse exemplo, qualquer menção ao conteúdo da mensagem da tia; aquilo que R1 julga como mau uso de norma culta, portanto, seria suficiente para avaliar a veracidade e a confiabilidade do texto. 
A escolha predominante por um critério que vincule a veracidade do conteúdo à correção gramatical parece-nos pautada, ainda que inconscientemente, naquilo que Bagno (1999) chama de "preconceito linguístico". Nesse sentido, o adequado, o aceitável, o bom, o belo estariam no domínio da obediência à norma culta; por conseguinte, aquilo que se desvia desse padrão seria errado, inconveniente, falso. Corrêa (2004) discorre, na introdução de seu trabalho, sobre a crença de que, "na escrita, não há variação sociolinguística", o que levaria a uma suposta "pureza da língua" (CORRÊA, 2004, p. XIII). Ora, é essa visão equivocada de pureza e correção que nos parece dialogar, no conjunto de material, com a avaliação feita pelos estudantes. Se a mensagem enviada pela tia é marcada "pela notável presença de erros ortográficos", conforme R1 (linhas 2 e 3), logo, sob a crença da invariabilidade da escrita, o conteúdo deve ser falso.

Se, por um lado, faz parte dos conteúdos curriculares o trabalho com a variação linguística em práticas sociais de oralidade e escrita, por outro, a própria $\mathrm{BNCC}$ reforça a primazia da escrita sobre outras formas de expressão: "Nessa perspectiva, para além da cultura do impresso (ou da palavra escrita), que deve continuar tendo centralidade na educação escolar, é preciso considerar a cultura digital, os multiletramentos, os novos letramentos, entre outras denominações que procuram designar novas práticas sociais e de linguagem.” (BNCC, 2018, p. 478). Uma vez que documentos que orientam a educação brasileira insistem no império da escrita, não é surpreendente, então, que os estudantes façam a leitura de que, à luz de certo senso comum, o que vale é o escrito - e, nesse domínio, o escrito considerado correto, belo e verdadeiro. A voz institucional que prioriza a palavra escrita e sua correção, portanto, atravessa a análise dos estudantes. 
Já o critério denominado como "experiência própria/ empirismo" é ilustrado no Texto 3. A produção do respondente - doravante, R2 - baseia-se em sua observação de mundo para afirmar que "A noticia que a tia mandou no grupo é mentira [...]" (linha 1). Ao longo do texto, não são apresentadas razões ou argumentos que ultrapassem a vivência particular do estudante - algumas delas, inclusive, sem respaldo sociocultural; na linha 7, por exemplo, é dito que "o facebook não tem nada a ver com o Whatsapp", embora a empresa de Mark Zuckerberg já seja proprietária do serviço de mensagens desde 2014.

\section{Texto 3 - produção de um respondente}

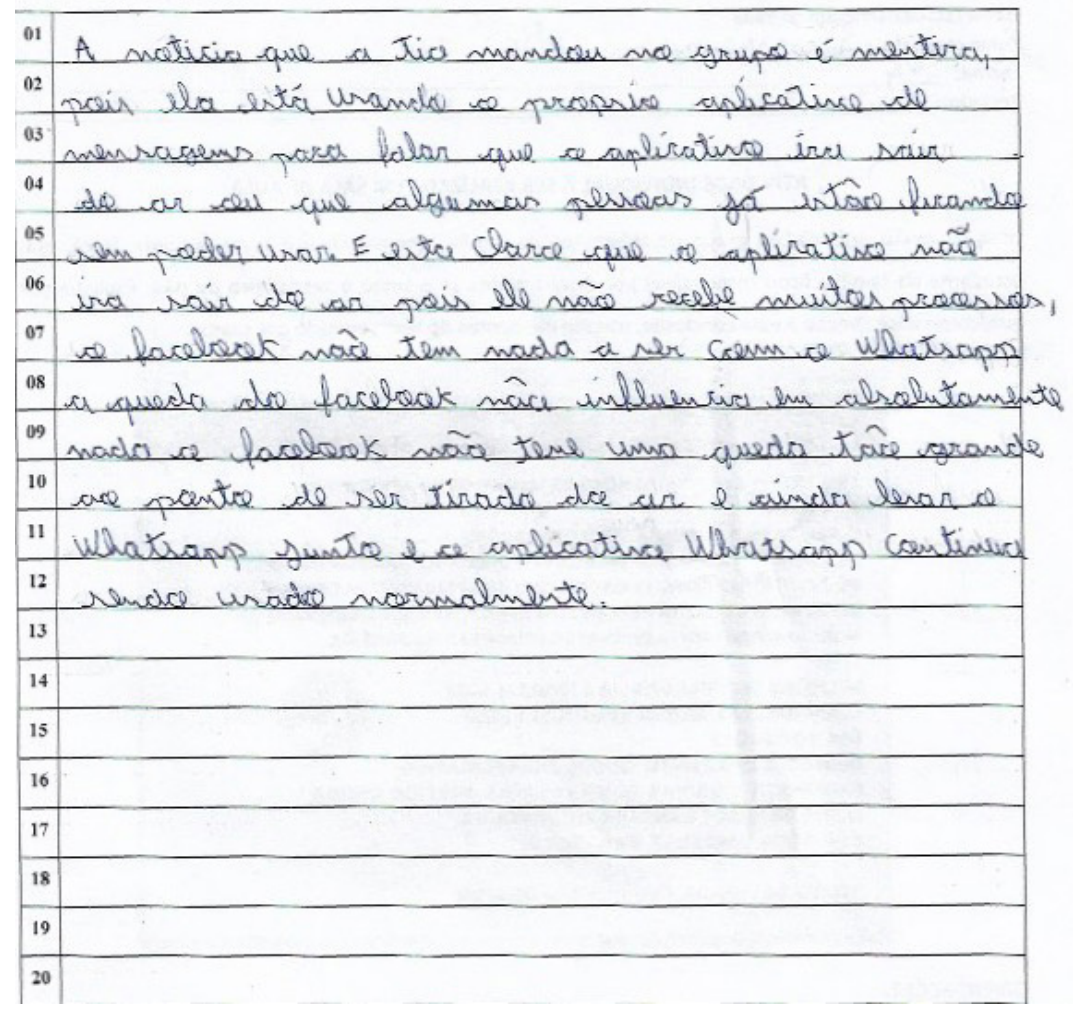

Fonte: Dados da pesquisa (2021) 
A leitura limitada ao empirismo parece dialogar, em certa medida, com uma postura negacionista. Como usuário do WhatsApp, R2 faz afirmações taxativas, baseadas naquilo que ele mesmo sabe, no papel de estudante da família; analogamente, crenças pessoais têm tanto ou mais valor argumentativo quanto a ciência. Com McIntyre (2018), analisamos ambas as posturas no contexto da "pós-verdade", de ascensão da opinião como parâmetro válido (quando não o único) de julgamento. Questionamos, ainda, se a leitura dos estudantes não ecoa, em certa medida, posturas institucionais (governamentais, educacionais, familiares) no sentido de reiterar o próprio discurso como verdadeiro, extinguindo-se a necessidade de aprofundamento, pesquisa e verificação de fonte. Num contexto em que presidentes acusam jornalistas de serem fake news por fazerem oposição a seus governos, os estudantes encontram respaldo para julgarem conteúdo como mentiroso baseados apenas em sua vivência.

Associada a esse fenômeno, pode-se apontar a chamada "sofisticação cognitiva" (tradução nossa para cognitive sophistication), discutida por Pennycook et al. (2020) em trabalho do MIT realizado durante a pandemia; caracterizada por pensamento analítico, numeramento, conhecimento científico básico e ceticismo, a falta dessa "sofisticação cognitiva" teria maior impacto na percepção equivocada a respeito da covid-19 e de conteúdos compartilhados sobre a doença, conforme a pesquisa. Pode-se pensar, então, que o julgamento por parte dos alunos de informação falsa baseada apenas em seu próprio conhecimento é pautado na falta de pensamento analítico e conhecimento científico; a justificativa acerca da mensagem enviada pela tia não ultrapassa o nível tautológico, portanto, por falta de "sofisticação" na elaboração da argumentação. 
A expectativa da BNCC (2018) é de um leitor autônomo, ativo, que usa de curadoria para avaliar, comentar e compartilhar aquilo que lê. As instituições, no entanto, não deveriam ignorar o fato de que o leitor, num modelo de letramento ideológico (STREET, 1984), não é senhor de suas escolhas e da construção dos sentidos que faz. Além disso, embora espere-se que o aluno perceba e discuta desinformação e pós-verdade, faz-se essencial lembrar que ele mesmo está inserido emocionalmente nesse dinâmica - portanto, mais do que avaliar conteúdo pautado em crenças alheias, suas próprias crenças estarão em jogo. Por fim, é preciso ultrapassar o nível linguístico-gramatical e a falácia da pureza da escrita, se se objetiva desenvolver habilidades leitoras realmente significativas no âmbito da desordem informacional.

\section{Considerações finais}

Num contexto pandêmico em que, de acordo com o relatório do Reuters Institute (NEWMAN, N. et al., 2021), $83 \%$ dos brasileiros recorrem a fontes online para informação, conteúdos produzidos sem o devido embasamento científico, mas que dialogam com o que é mais próximo e confortável à crença de cada usuário, constituem, de fato, um intrincado ciclo infodêmico. Some-se o fato de o Brasil ser o país que menos demonstra confiança em cientistas, de acordo com uma pesquisa do Pew Research Center (instituição investigativa não partidária sobre questões, atitudes e tendências mundiais) conduzida entre outubro de 2019 e março de 2020 com mais de 20 países.

Faz-se necessário, portanto, discutir os letramentos e seu papel na relação com tal tipo de conteúdo, particularmente no tocante à covid-19, mas não apenas. A BNCC (2018) trata do desenvolvimento da competência leitora e discute a importância 
da vivência de experiências com práticas de linguagem em diversas mídias, apontando a cultura digital e os multiletramentos como aspectos a serem considerados na educação escolar. $\mathrm{O}$ documento aborda não só o aparecimento de gêneros digitais e convivência de mídia, mas a ascensão de novas possibilidades na construção de sentidos e na assunção dos papéis de produtor e leitor de um texto. Compreende, portanto, o contexto em que se dá a chamada desordem informacional como alvo urgente na formação dos estudantes brasileiros no que diz respeito aos letramentos, em especial o digital.

O letramento digital, tradicionalmente, relaciona-se à interação com a informação em termos de confirmar sua veracidade e credibilidade. No entanto, de acordo com Lankshear e Knobel (2015), o entendimento de tal letramento à luz unicamente da relação com a verdade é limitado; a informação, conforme os autores, torna-se um recurso no qual a preocupação com a verdade é substituída por relações e participação social. Trata-se, assim, de um entendimento do letramento sob viés sociocultural, em contraste com o modelo autônomo segundo o qual a leitura, o entendimento e o julgamento da veracidade de determinada informação se dariam meramente à luz de técnicas e habilidades em contexto digital. Vale destacar também a definição de letramento digital da Ontario Association for Media Literacy (Associação de Ontário para o Letramento Midiático) destacada por Duncan (2006 apud KOLTAY, 2011), que enfatiza o aspecto educacional: "É a educação que objetiva potencializar o entendimento e o aproveitamento dos estudantes sobre como a mídia funciona, produz sentido, é organizada e constrói a realidade" (DUNCAN, 2006 apud KOLTAY, 2011, p. 213). ${ }^{6}$

6 No original, em inglês: "It is education that aims to increase students' understanding and enjoyment of how the media work, how they produce meaning, how they are organized, and how they construct reality $[\ldots]$ ". 
É nesse sentido, então, que acreditamos ser pertinente direcionar a formação do estudante brasileiro quanto à competência em práticas sociais de leitura e escrita. A análise do conjunto de material nos mostrou que as instituições escolares não apenas devem se basear nas orientações da BNCC (2018), mas precisam, também, ultrapassar a leitura conteudista e presa a critérios apenas linguísticos - sob pena não só de incorrer em preconceito linguístico, mas também de reduzir a identificação de conteúdo verdadeiro e falso, no contexto da desordem informacional, àquilo que está escrito em total obediência à norma culta. Convém, ainda, uma abordagem mais ampla dos letramentos para além do impresso, escrito ou mesmo digital. Urge a compreensão do fenômeno da pós-verdade e da ascensão do negacionismo como contextos em que os alunos se inserem como sujeitos, não apenas como meros observadores e analistas.

Por fim, vale ressaltar que a formação do leitor no contexto da desordem informacional, com o objetivo de combatê-la, deveria constituir uma política pública, e não apenas uma iniciativa isolada em projetos escolares pontuais. O papel do leitor na avaliação e combate à desinformação não se restringirá à pandemia da covid-19 - a infodemia, possivelmente, não se encerrará com a inoculação vacinal.

\section{Referências}

ABAURRE, M. B. M. et al. Considerações sobre a utilização de um paradigma indiciário na análise de episódios de refacção textual. Trabalhos em Linguística Aplicada, Campinas, SP, v. 25, 2012. Disponível em: https://periodicos.sbu.unicamp.br/ojs/ index.php/tla/article/view/8639237. Acesso em: 8 jul. 2021. 
BAGNO, M. Preconceito linguístico: o que é, como se faz. Edições Loyola, 1999.

BRASIL. Lei de Diretrizes e Bases da Educação Nacional. Brasília: Senado Federal, 1996.

BRASIL. Lei $n^{0} 13.005$, de 25 de junho de 2014. Aprova o Plano Nacional de Educação (PNE) e dá outras providências. 2. ed. Brasília: Câmara dos Deputados, Edição Câmara, 2015. Disponível em: http://bd.camara.gov.br/bd/bitstream/handle/ bdcamara/20204/plano_nacional_educacao_2014-2024_2ed. pdf? sequence=8. Acesso em: 30 jun. 2021.

BRASIL. Base Nacional Comum Curricular: Ensino Médio. Brasília: MEC/Secretaria de Educação Básica, 2018.

COMITÊ GESTOR DA INTERNET NO BRASIL. Painel TIC COVID-19. 3. ed. 2020. Disponível em: https://cetic. br/media/docs/publicacoes/2/20201104182616/painel_tic_ covid19_3edicao_livro\%20eletr\%C3\%B4nico.pdf. Acesso em: 29 jun. 2021.

CORRÊA, M. L. G. O modo heterogêneo de constituição da escrita. São Paulo: Martins Fontes, 2004.

EUROPEAN COMMISSION. A multi-dimensional approach to disinformation. Report of the independent High level Group on fake news and online disinformation. Disponível em: https://ec.europa.eu/digital-single-market/en/news/final-reporthigh-level-expert-group-fake-news-and-online-disinformation. Acesso em: 29 jun. 2021.

$68^{\circ}$ GEL - Mesa-redonda: Linguagens e BNCC. São Carlos, jul. 2021. 1 vídeo (2h20m43s). Publicado por Grupo de Estudos Linguísticos do Estado de São Paulo. Disponível em: https:// www.youtube.com/watch? $v=c t K A W S Q X h n k$. Acesso em 8 jul. 2021.

GALHARDI, C. P. et al. M. Fato ou Fake? Uma análise da desinformação frente à pandemia da COVID-19 no Brasil. 
Ciência \& Saúde Coletiva, Rio de Janeiro, v. 25, supl. 2, p. 42014210, out. 2020. Disponível em: http://www.scielo.br/scielo. php?script=sci_arttext\&pid=S1413-81232020006804201\&lng= en\&nrm=iso. Acesso em: 30 jun.2021.

GINZBURG, C. Sinais: raízes de um paradigma indiciário. In: GINZBURG, Carlo. Mitos, emblemas, sinais: morfologia e história. Tradução de Frederico Carotti. São Paulo: Companhia das Letras, 1989. p. 143-179.

GONTIJO, C. M. M. Base Nacional Comum Curricular (BNCC): comentários críticos. Revista Brasileira de Alfabetização, v. 1, n. 2, p. 174-190, jul./dez. 2015.

ISLAM, M. S. et al. COVID-19-Related infodemic and Its impact on public health: A global social media analysis. The American Journal of Tropical Medicine and Hygiene, v. 103, n. 4, p. 1621-1629, 2020.

JOHNS HOPKINS. COVID-19 Dashboard by the Center for Systems Science and Engineering (CSSE). 2020. Disponível em: https://coronavirus.jhu.edu/map.html. Acesso em: 27 jun. 2021.

KOLTAY, T. The media and the literacies: media literacy, information literacy, digital literacy. Media, Culture \& Society, v. 33, n. 2, p. 211-221, 2011.

KOMESU, F.; DAUNAY, B.; FLUCKIGER, C. Littéracies numériques et désinformation: le rôle de l'enseignant dans le contexte d'infodémie. In: SCHEEPERS, C. (org.). Former à l'écrit, former par l'écrit. Paris: De Boeck. No prelo.

LANKSHEAR, C; KNOBEL, M. Digital Literacy and Digital Literacies: Policy, Pedagogy and Research Considerations for Education. Nordic Journal of Digital Literacy, p. 8-20, 2015.

MCINTYRE, L. Post-Truth. Massachusetts: MIT Press, 2018.

MOREIRA, A. F. (org.). Ênfases e Omissões no Currículo. Campinas: Papirus Editora, 2001. 
MORGADO, J. C. Projecto curricular e autonomia da escola: das intenções às práticas. Revista Brasileira de Política e Administração da Educação - Periódico científico editado pela ANPAE, [S.l.], v. 27, n. 3, mar. 2012. Disponível em: https://seer.ufrgs.br/rbpae/article/view/26411/15403. Acesso em: 29 jun. 2021.

PENNYCOOK, G. et al. Predictors of attitudes and misperceptions about COVID-19 in Canada, the UK, and the USA. PsyArXiv, v. 10, p. 1-25, 2020.

UNIVERSIDADE FEDERAL FLUMINENSE. Debates e controvérsias em torna da Base Nacional Comum Curricular (BNCC). Movimento-Revista de Educação, n. 8, p. 268280, jan./jun. 2018. Disponível em: https://periodicos.uff.br/ revistamovimento/article/view/32656/18791. Acesso em 30 jun. 2021.

NEWMAN, N. et al. Reuters Institute: Digital News Report 2021. London: Reuters Institute; University of Oxford, 2021. Disponível em: https://reutersinstitute.politics.ox.ac.uk/sites/ default/files/2021-06/Digital_News_Report_2021_FINAL.pdf. Acesso em: 26 jun. 2021.

PEW RESEARCH CENTER. Science and Scientists Held in High Esteem Across Global Publics. Disponível em: https://www.pewresearch.org/science/2020/09/29/science-andscientists-held-in-high-esteem-across-global-publics. Acesso em 27. jun. 2021.

SILVA, M. R. Currículo, ensino médio e BNCC: um cenário de disputas. Revista Retratos da Escola. Brasília, v. 9, n. 17, p. 367-379, jul./dez. 2015.

STREET, B. Literacy in theory and practice. Cambridge: Cambridge University Press, 1984.

TANDOC JR., E. C.; LIM, Z. W.; LING, R. Defining "Fake News". Digital Journalism, v. 6, n. 2, p. 137-153, 2018. 
WARDLE, C.; DERAKHSHAN, H. Conceptual Framework. In: WARDLE, C.; DERAKHSHAN, H. Information Disorder: toward an interdisciplinar framework for research and policy making. Council of Europe Report, DGI, 2017. p. 20-48. WE ARE SOCIAL. Global Digital Report 2019. Disponível em: https://wearesocial.com/digital- 2021. Acesso em 30 de jun. de 2021.

UNESCO. Alfabetização midiática e informacional (AMI). 2019. Disponível em: http://www.unesco.org/new/pt/brasilia/ communication-and-information/digital-transformation-andinnovation/media-and-information-literacy. Acesso em: 29 jun. 2021.

ZAROCOSTAS, J. How to fight an infodemic. The Lancet, v. 395, n. 10225, 2020. 